\title{
COMPOSTAGEM E VERMICOMPOSTAGEM DE DEJETOS DE CAPRINOS: EFEITO DAS ESTAÇÕES DO ANO
}

\author{
ANA C. AMORIM², JORGE DE LUCAS JÚNIOR ${ }^{3}$, KLEBER T. DE RESENDE ${ }^{4}$
}

RESUMO: A caprinocultura brasileira cresceu consideravelmente nos últimos anos, elevando a produção de resíduos, fato que justifica o estudo de práticas de reciclagem, tais como a compostagem e a vermicompostagem, pois, além da agregação de valor com a produção do composto, representa um meio de saneamento na área rural. Para o desenvolvimento deste trabalho, foram utilizados dejetos coletados de caprinos em diferentes faixas etárias, mantidos em sistema de semiconfinamento e com regime alimentar único. O objetivo principal foi avaliar os efeitos das estações do ano sobre os processos de compostagem e vermicompostagem. As reduções na quantidade de matéria seca (MS) foram de 53,7; 53,4; 51,4 e 47,8\% para a compostagem e 57,4;51,0;41,4 e 53,6\% para a vermicompostagem nas estações de verão, outono, inverno e primavera, respectivamente. Observaramse maiores reduções na relação $\mathrm{C} / \mathrm{N}$ durante o verão e outono, em relação à primavera e ao inverno, para ambos os processos. As equações de redução de volume, na compostagem, foram: $\mathrm{y}=-0,0512 \mathrm{x}+$ 1,$0233 ; \mathrm{y}=-0,0552 \mathrm{x}+1,1766 ; \mathrm{y}=-0,0521 \mathrm{x}+1,1656$ e $\mathrm{y}=-0,0558 \mathrm{x}+1,3227$, para as estações primavera, outono, inverno e verão, respectivamente, $\left(\mathrm{x}=\right.$ número de semanas e $\mathrm{y}=$ volume, $\left.\mathrm{em}^{3}{ }^{3}\right)$.

PALAVRAS-CHAVE: estações do ano, leira, relação C/N.

\section{COMPOSTING AND VERMICOMPOSTING CAPRINE DEJECTIONS: EFFECT OF SEASON}

\begin{abstract}
Brazilian caprine raising has grown considerably in the last years and has elevated the waste production, what justifies the study of recycling practices of composting and vemicomposting because their aggregation values with the fertilizers production, and also represent a sanitation way in the rural zone. In this study, caprines of different ages, maintained in semi confinement system and with the same diet feeding were used. The main objective was evaluating the effect of the season on the composting and vermicomposting process. The dry matter reduction was of $53.7 ; 53.4 ; 51.4$ and $47.8 \%$ for composting process and 57.4; 51.0; 41.4 and 53.6\% for vermicomposting in Summer, Autumn, Winter and Spring respectively. Larger reductions were observed in the $\mathrm{C} / \mathrm{N}$ ratio during Summer and Autumn in relation to Spring and Winter, for both processes. The equations of volume reduction in the composting process were: $y=-0.0512 x+1.0233 ; y=-0.0552 x+1.1766 ; y=-0.0521 x$ +1.1656 and $\mathrm{y}=-0.0558 \mathrm{x}+1.3227$ for Spring, Autumn, Winter and Summer, respectively $(\mathrm{x}=$ number of weeks and $\mathrm{y}=$ volume in $\mathrm{m}^{3}$ ).
\end{abstract}

KEYWORDS: seasons, piles, C/N ratio.

\section{INTRODUÇÃO}

Uma estratégia para prosseguir com o desenvolvimento mundial sem que haja o comprometimento das reservas energéticas de gerações futuras e o aumento do impacto ambiental, ocasionado pela disposição inadequada dos resíduos gerados nos sistemas produtivos, dá-se com a

\footnotetext{
${ }^{1}$ Extraído da dissertação de Mestrado da primeira autora . Projeto financiado pela FAPESP.

${ }^{2}$ Zootecnista, Aluna de Doutorado, Programa de Produção Animal, UNESP, Jaboticabal - SP, amorim@ fcav.unesp.br

${ }^{3}$ Eng ${ }^{\mathrm{o}}$ Agrônomo, Prof. Titular, Departamento de Engenharia Rural, UNESP, Jaboticabal - SP, jlucas@ fcav.unesp.br

${ }^{4}$ Zootecnista, Prof. Adjunto, Departamento de Zootecnia, UNESP - Jaboticabal - SP.

Recebido pelo Conselho Editorial em: 13-2-2003

Aprovado pelo Conselho Editorial em: 25-10-2004
} 
adoção de sistemas de reciclagem desses resíduos, promovendo-se a geração de energia renovável e/ou a estabilização da matéria orgânica para uso como composto.

Dentre as diversas espécies destinadas à produção animal, os caprinos merecem destaque, principalmente pelo aumento nos plantéis observado nos últimos anos. Segundo levantamento realizado pela FAO (2000), a população mundial de caprinos é de aproximadamente 700 milhões de cabeças, e cerca de $92 \%$ desses estão distribuídos nas regiões em desenvolvimento: tropicais e subtropicais.

O emprego de práticas como compostagem e vermicompostagem em dejetos de origem animal é de extrema importância, pois garante um destino apropriado a esse material, preservando o ambiente e possibilitando sua comercialização, fato que representa uma fonte de renda alternativa. Além disso, essas práticas contribuem para o saneamento, reduzindo o número de patógenos durante a fase termofílica da compostagem.

O composto é resultante de um processo controlado de decomposição bioquímica de materiais orgânicos (compostagem), sendo um produto mais estável e utilizado como fertilizante (KIEHL, 1985). Como processo biológico e dentro de uma concepção moderna, a compostagem deve ser necessariamente aeróbia e incluir uma fase termofílica $\left(45-65^{\circ} \mathrm{C}\right)$, quando será maximizada a atividade microbiológica de degradação e higienização (primeira fase do processo), e a fase de maturação ou cura, quando ocorrem a humificação e a produção do composto propriamente dito, que é a segunda fase do processo (PEREIRA NETO \& STENTIFORD, 1992). Ainda, segundo os mesmos autores, a compostagem é o processo de tratamento de resíduos que apresenta maior flexibilidade operacional, combinando baixo custo e alta eficiência em um só sistema.

No processo de vermicompostagem, o produto final pode ser definido como adubo orgânico, obtido com o uso de substratos de origem animal e/ou vegetal, pré-compostados e, posteriormente, processados por minhocas. A partir daí, é produzido o húmus, um composto coloidal rico em nutrientes, principalmente nitrogênio, cálcio, fósforo, magnésio e potássio, oriundos das dejeções das minhocas. Assim como na compostagem, para a vermicompostagem, são requeridos controles de umidade, temperatura e $\mathrm{pH}$. O objetivo desse processo é melhorar as características físico-químicas e biológicas do composto e, conseqüentemente, melhorar sua aceitação e seu valor comercial (KNAPPER, 1987).

Em estudo realizado por GORGATI (2001), efetuou-se a compostagem de lixo urbano nas quatro estações do ano, observando-se diferenças significativas da reciclagem em diferentes épocas do ano. Portanto, justifica-se estudar o desenvolvimento da compostagem e da vermicompostagem nas estações do ano, visto que, na literatura, são bastante limitadas as informações sobre esses processos com dejetos de caprinos.

Com base na importância da reciclagem e tratamento dos resíduos gerados na caprinocultura, tevese o objetivo de avaliar as diferenças na qualidade dos dejetos gerados por caprinos, nas quatro estações do ano, e as possíveis influências sobre os processos de compostagem e vermicompostagem.

\section{MATERIAL E MÉTODOS}

\section{Descrição do local}

O trabalho foi realizado no Laboratório de Digestão Anaeróbia do Departamento de Engenharia Rural, utilizando-se dos dejetos gerados no Setor de Caprinocultura do Departamento de Zootecnia, ambos pertencentes à UNESP - Câmpus de Jaboticabal, situado em local cujas coordenadas geográficas são: $21^{\circ} 14^{\prime} 05^{\prime \prime} \mathrm{S} ; 48^{\circ} 17^{\prime} 09^{\prime \prime} \mathrm{W}$ e altitude média de $613 \mathrm{~m}$. 
O clima da região, segundo a classificação de Köeppen, é Aw com transição para Cwa. De acordo com as normais (1971-2000) observadas em Jaboticabal, o clima caracteriza-se por ser subtropical úmido, seco no inverno e com chuvas no verão, com precipitação anual de 1.424,6 mm, temperatura média anual de $22,2{ }^{\circ} \mathrm{C}$ e umidade relativa média anual de $70,8 \%$.

Na Tabela 1, estão apresentados os dados climáticos observados na cidade de Jaboticabal, durante a execução deste trabalho.

TABELA 1. Dados meteorológicos mensais do ano de 2001.

\begin{tabular}{lcccc}
\hline Mês / 2001 & Tmáx $\left({ }^{\circ} \mathrm{C}\right)$ & Tmín $\left({ }^{\circ} \mathrm{C}\right)$ & Tméd $\left({ }^{\circ} \mathrm{C}\right)$ & UR $(\%)$ \\
\hline janeiro & 32,0 & 19,7 & 24,8 & 75,7 \\
fevereiro & 32,1 & 20,4 & 25,0 & 78,0 \\
março & 31,4 & 19,5 & 24,5 & 76,3 \\
abril & 30,9 & 18,0 & 23,8 & 70,9 \\
maio & 26,6 & 14,0 & 19,5 & 75,7 \\
junho & 26,3 & 12,9 & 18,8 & 73,0 \\
julho & 28,1 & 13,2 & 20,0 & 64,9 \\
agosto & 28,9 & 14,0 & 21,0 & 57,3 \\
setembro & 29,7 & 16,4 & 22,4 & 61,2 \\
outubro & 30,4 & 17,7 & 23,5 & 64,8 \\
novembro & 30,7 & 19,7 & 24,4 & 73,3 \\
dezembro & 29,4 & 19,2 & 23,6 & 77,1 \\
\hline Média anual & 29,7 & 17,1 & 22,6 & 70,7 \\
\hline
\end{tabular}

Tmáx: temperatura máxima; Tmín: temperatura mínima; Tméd: temperatura média; UR: umidade relativa do ar.

Fonte: Estação Agroclimatológica da UNESP - Câmpus de Jaboticabal, 2001.

\section{Ensaio de compostagem}

Foram confeccionadas três leiras de compostagem para cada estação do ano. Para a formação das leiras nas estações, foi estabelecido como padrão a colheita dos dejetos gerados em sete dias, coletando-se, sucessivamente, até atingir a quantidade desejada para que fossem montadas as leiras. Após a colheita, o material foi esparramado numa camada de $2 \mathrm{~cm}$ sobre lonas plásticas que foram estendidas no chão e coberto com a lona excedente. Esse procedimento evitou a fermentação excessiva até que fosse atingida a quantidade ideal para a formação das três leiras na respectiva estação. Todo o material coletado foi misturado, peneirado em peneira com malha de aproximadamente $1 \mathrm{~cm}$ para a quebra das cíbalas e a obtenção de maior homogeneidade. Foram coletadas amostras desse material peneirado para análise de sólidos totais, e os dejetos com umidade acima do desejável (estações de verão e primavera) foram mantidos estendidos sobre as lonas até que se atingisse teor desejável de sólidos totais para a confecção das leiras, aproximadamente $40 \%$.

A altura inicial de cada leira foi em torno de $1 \mathrm{~m}$ e a largura de 1,5 m, como recomendado por KIEHL (1985), e o comprimento médio inicial de $1,8 \mathrm{~m}$. O material enleirado foi pesado e medido semanalmente, com auxílio de trena, a fim de proporcionar a obtenção de equações representativas quanto à redução de volume das leiras durante o período de 90 dias.

Adotaram-se revolvimentos duas vezes por semana durante a primeira quinzena, após o enleiramento, e revolvimentos semanais, após esse período, sendo coletadas amostras semanais para acompanhamento da umidade do composto e estimativa de redução da massa seca. Quando necessário, promoveu-se a elevação da umidade com adição de água, ressaltando-se que não houve a formação de chorume, pois, apesar de as leiras serem manejadas ao ar livre, quando chovia, as mesmas eram 
cobertas. As medições de temperatura foram efetuadas diariamente, em torno de 8 h 30, no interior das leiras, utilizando-se de termômetro digital com haste metálica.

$\mathrm{Na}$ formação das leiras e final do período de compostagem, coletaram-se amostras para a determinação dos teores de sólidos totais e voláteis, carbono e nitrogênio.

\section{Ensaio de vermicompostagem}

Da mesma forma como descrita no processo de compostagem, adotou-se também a confecção de três leiras para cada estação, após o peneiramento da massa de dejetos.

A altura inicial de cada leira foi em torno de 1,5 m, largura de 1,5 m e comprimento médio inicial de 1,2 m. Foram adotados revolvimentos duas vezes na semana, no período de compostagem.

Após 30 dias, o material enleirado foi transferido para o canteiro de vermicompostagem com a altura de empilhamento reduzida a $0,5 \mathrm{~m}$. Em seguida, foram adicionados aproximadamente $3 \mathrm{~L}$ de minhocas (Eisenia foetida) por $\mathrm{m}^{3}$ de material compostado. Os canteiros foram cobertos com sombrite, para que diminuísse a incidência de luz, e as minhocas pudessem percorrer o material enleirado por igual, deixando de dar preferência ao fundo do canteiro. $\mathrm{O}$ material foi mantido nos canteiros por 60 dias, totalizando 90 dias.

Efetuaram-se pesagens semanais da massa enleirada, durante os 30 primeiros dias, e no final do processo. Foram coletadas amostras semanalmente para acompanhamento da umidade e, quando necessário, adicionou-se água. Na formação das leiras e final do período de vermicompostagem, coletaram-se amostras para a determinação dos teores de sólidos totais e voláteis, carbono e nitrogênio.

\section{Análises laboratoriais}

Os teores de sólidos totais (ST) e sólidos voláteis (SV) das amostras de dejetos foram determinados segundo metodologia descrita em APHA (1995).

Para a determinação dos teores de nitrogênio $(\mathrm{N})$, utilizou-se do extrato obtido a partir da digestão sulfúrica em digestor Digesdahl Hach. Com esse extrato e por meio do destilador de microKjeldahl, determinou-se a concentração de N total, conforme metodologia descrita por SILVA (1981).

Nas amostras coletadas das leiras de compostagem e vermicompostagem, foram quantificados os teores de C orgânico, conforme descrito por KIEHL (1985). O método oferece a vantagem de não oxidar a fração de matéria orgânica não-decomponível durante o processo.

\section{Análise estatística}

Os dados gerados nos ensaios de compostagem e vermicompostagem tiveram suas médias comparadas pelo teste de Tukey, a 5\% de probabilidade, adotando-se delineamento inteiramente casualizado, com três repetições.

\section{RESULTADOS E DISCUSSÃO}

\section{Compostagem}

Os resultados obtidos na compostagem durante as estações de verão, outono, inverno e primavera estão apresentados na Tabela 2 .

Um importante índice a ser observado é a porcentagem de redução de MS, que foi maior $(\mathrm{P}<0,05)$ nas leiras conduzidas durante as estações de verão e outono $(54,6$ e $51,6 \%$, respectivamente), em relação às manejadas durante o inverno e primavera, com médias de 49,2 e $48,8 \%$, respectivamente. 
Esses valores podem ser comparados aos obtidos por GORGATI (2001) em trabalhos realizados com compostagem de lixo urbano, quando obteve reduções médias de 53,1 e 52,9\% em leiras cobertas e descobertas, respectivamente. Segundo KIEHL (1985), a redução esperada deve ser de aproximadamente $50 \%$.

TABELA 2. Quantidade (em kg) de massa seca (MS), porcentagem de sólidos totais (ST) e voláteis (SV) do esterco enleirado e do composto e redução (\%) da quantidade de MS, para as diferentes estações do ano.

\begin{tabular}{clcccc}
\hline Parâmetros & \multicolumn{1}{c}{ Período } & Verão & Outono & Inverno & Primavera \\
\hline \multirow{2}{*}{ MS } & Enleiramento & $202,3 \mathrm{AB}$ & $278,9 \mathrm{~A}$ & $237,5 \mathrm{AB}$ & $147,3 \mathrm{~B}$ \\
& Final & $91,9 \mathrm{~B}$ & $134,9 \mathrm{~A}$ & $120,7 \mathrm{~A}$ & $75,4 \mathrm{~B}$ \\
\hline \multirow{2}{*}{$\mathrm{ST}$} & Redução de MS & $54,6 \mathrm{~A}$ & $51,6 \mathrm{~A}$ & $49,2 \mathrm{~B}$ & $48,8 \mathrm{~B}$ \\
& Enleiramento & $21,4 \mathrm{~B}$ & $39,3 \mathrm{~A}$ & $41,3^{\mathrm{a}}$ & $20,0 \mathrm{~B}$ \\
& Final & $32,6 \mathrm{~B}$ & $56,7 \mathrm{~A}$ & $50,9^{\mathrm{a}}$ & $54,3 \mathrm{~A}$ \\
\hline \multirow{2}{*}{$\mathrm{SV}$} & Enleiramento & $79,5 \mathrm{~B}$ & $76,5 \mathrm{~B}$ & $81,0 \mathrm{~B}$ & $89,7 \mathrm{~A}$ \\
& Final & $64,7 \mathrm{~B}$ & $67,4 \mathrm{~B}$ & $61,8 \mathrm{~B}$ & $73,5 \mathrm{~A}$ \\
\hline
\end{tabular}

Médias seguidas de diferentes letras, na linha, diferem entre si, pelo teste de Tukey $(\mathrm{P}<0,05)$.

Os dados representados na Figura 1 referem-se às temperaturas médias diárias, nas leiras de compostagem, nas quatro estações do ano. Observa-se que as temperaturas máximas ocorreram durante os primeiros 20 dias de compostagem. É possível observar ainda que, com aproximadamente 30 dias de formação das leiras, nas estações de verão e outono, as temperaturas atingiram valores inferiores a $30^{\circ} \mathrm{C}$, comportamento não observado nas leiras de inverno e primavera.

THAMBIRAJAH et al. (1995) avaliaram a compostagem de mistura obtida a partir dos resíduos de extração de óleo de palma e dejetos de caprinos (90:25 kg, respectivamente) e obtiveram temperaturas abaixo de $40^{\circ} \mathrm{C}$ após os primeiros 25 dias de compostagem, e o pico de temperatura ocorreu com quatro dias de enleiramento, sendo de $70^{\circ} \mathrm{C}$. Em experimento realizado por HANAJIMA et al. (2001), a temperatura máxima observada foi de $65,9^{\circ} \mathrm{C}$, usando esterco bovino como substrato para a formação das leiras.

Na Tabela 3, estão apresentados os teores médios de carbono, nitrogênio e relação $\mathrm{C} / \mathrm{N}$ (valores com base na MS) do esterco enleirado para compostagem e do composto obtido nas diferentes estações do ano.

Observa-se efeito $(\mathrm{P}<0,05)$ das estações do ano (Tabela 3 ) sobre os teores iniciais e finais de $\mathrm{C}$ e $\mathrm{N}$ e no declínio da relação $\mathrm{C} / \mathrm{N}$, ao longo do período de compostagem. As diferenças nos conteúdos de $\mathrm{C}$ e $\mathrm{N}$ nos dejetos podem estar relacionadas com o efeito da sazonalidade na produção dos alimentos, visto que, durante o período da seca, que compreende a estação de inverno e parte da primavera, há menor incidência de chuvas e, portanto, maior dificuldade na produção de forragens, acarretando em perdas de qualidade e quantidade. A qualidade da fração carbono será depreciada pelo incremento de parede celular e redução de conteúdo celular na composição das forragens; já o nitrogênio poderá ter sua disponibilidade reduzida, visto que poderá estar associado à fração fibrosa. Esses parâmetros colaboram para a redução da digestibilidade dos alimentos e conseqüente enriquecimento das fezes; no entanto, esse incremento não significa melhoria na composição dos dejetos. 


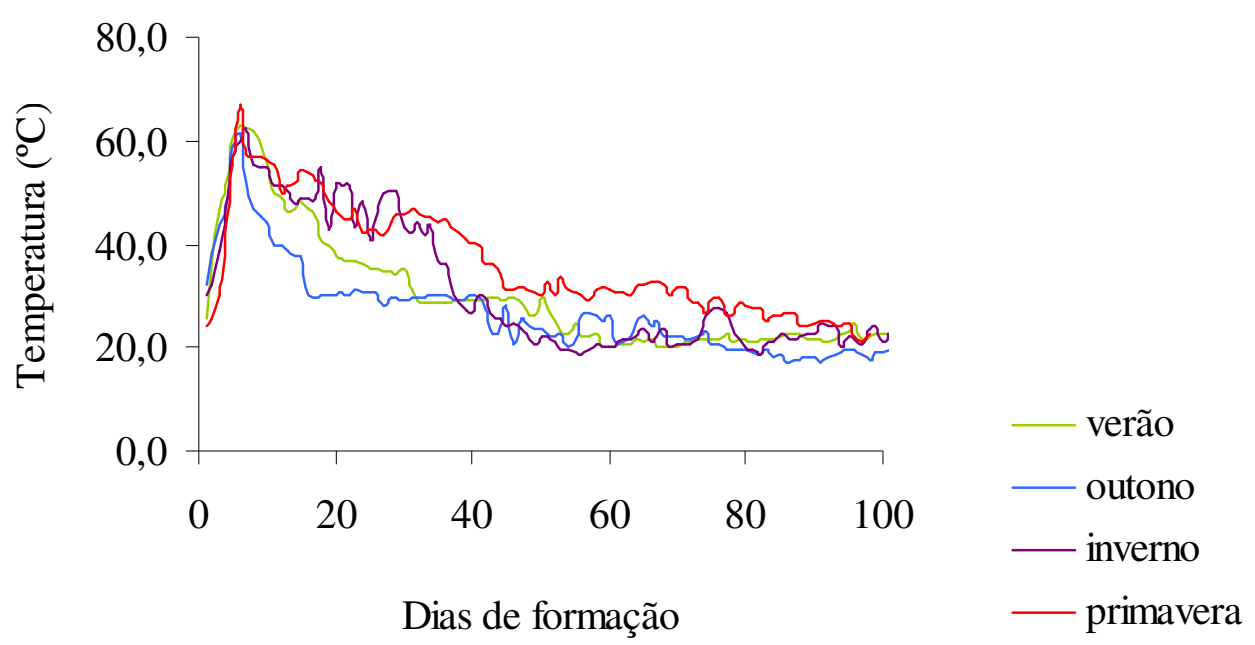

FIGURA 1. Temperaturas diárias das leiras de compostagem nas estações de verão, outono, inverno e primavera.

TABELA 3. Teores médios de carbono, nitrogênio e relação C/N (\% da MS), do esterco enleirado para compostagem e do composto no verão, outono, inverno e primavera.

\begin{tabular}{clrrrc}
\hline Atributo & \multicolumn{1}{c}{ Fase } & Verão & Outono & Inverno & Primavera \\
\hline \multirow{2}{*}{$\mathrm{C}$} & Enleiramento & $18,4 \mathrm{C}$ & $22,9 \mathrm{~B}$ & $27,1 \mathrm{~A}$ & $26,2 \mathrm{~A}$ \\
& Final & $3,4 \mathrm{~B}$ & $4,2 \mathrm{~B}$ & $8,6 \mathrm{~A}$ & $8,9 \mathrm{~A}$ \\
\hline \multirow{2}{*}{$\mathrm{N}$} & Enleiramento & $1,1 \mathrm{C}$ & $1,3 \mathrm{~B}$ & $1,6 \mathrm{~A}$ & $1,6 \mathrm{~A}$ \\
& Final & $0,6 \mathrm{~B}$ & $0,7 \mathrm{~B}$ & $1,0 \mathrm{~A}$ & $1,1 \mathrm{~A}$ \\
\hline \multirow{2}{*}{ Relação C/N } & Enleiramento & 17,0 & 17,0 & 17,2 & 16,3 \\
& Final & 6,1 & 6,2 & 8,4 & 8,2 \\
\hline \multicolumn{2}{l}{ Porcentagem de Redução } & $64,3 \mathrm{~A}$ & $63,7 \mathrm{~A}$ & $51,3 \mathrm{~B}$ & $49,9 \mathrm{~B}$ \\
\hline
\end{tabular}

Médias seguidas de diferentes letras, na linha, diferem entre si, pelo teste de Tukey $(\mathrm{P}<0,05)$.

Durante o verão e outono, ocorreram as maiores reduções na relação C/N, em média 63,99\%, sendo que as demais estações apresentaram reduções inferiores, não diferindo $(\mathrm{P}<0,05)$ entre si. Essa redução mais intensa durante o verão e outono pode estar intimamente relacionada à qualidade dos dejetos e às condições climáticas durante ambas as estações, conforme representado pelo comportamento da temperatura, que pode ter proporcionado maiores taxas de degradação e, consequientemente, maior redução da relação $\mathrm{C} / \mathrm{N}$. As relações $\mathrm{C} / \mathrm{N}$ encontradas neste trabalho são inferiores às obtidas por THAMBIRAJAH et al. (1995), que foram de 52:1 e 24:1, no início e final da compostagem de uma mistura à base de resíduo de extração do óleo de palma e dejeto de cabras, respectivamente.

A relação $\mathrm{C} / \mathrm{N}$ do composto (final) apresentou-se inferior à definida como ideal por LOPEZREAL (1990), citado por GORGATI (2001), que é de 10:1. No entanto, GORGATI (2001) encontrou no composto obtido de lixo urbano, relação $\mathrm{C} / \mathrm{N}$ de 6,6 em leiras cobertas e de 11,0 em leiras manejadas sem cobertura.

As tendências e equações de reduções de volume das leiras de compostagem desenvolvidas durante as estações de verão, outono, inverno e primavera estão representadas na Figura 2. Apesar de haver diferenças $(\mathrm{P}<0,05)$ nas reduções dos volumes, maiores em leiras conduzidas durante o verão e 
o outono (médias de 68,0 e 67,7\%, respectivamente), se comparadas com as de inverno e primavera (médias de 64,1 e 65,1\%, respectivamente), a tendência de diminuição do volume (Figura 2) foi linear em todas as estações. As diferenças de redução do volume durante a compostagem podem estar relacionadas com a qualidade do material inicial, determinada principalmente pela composição das frações carbono e nitrogênio.

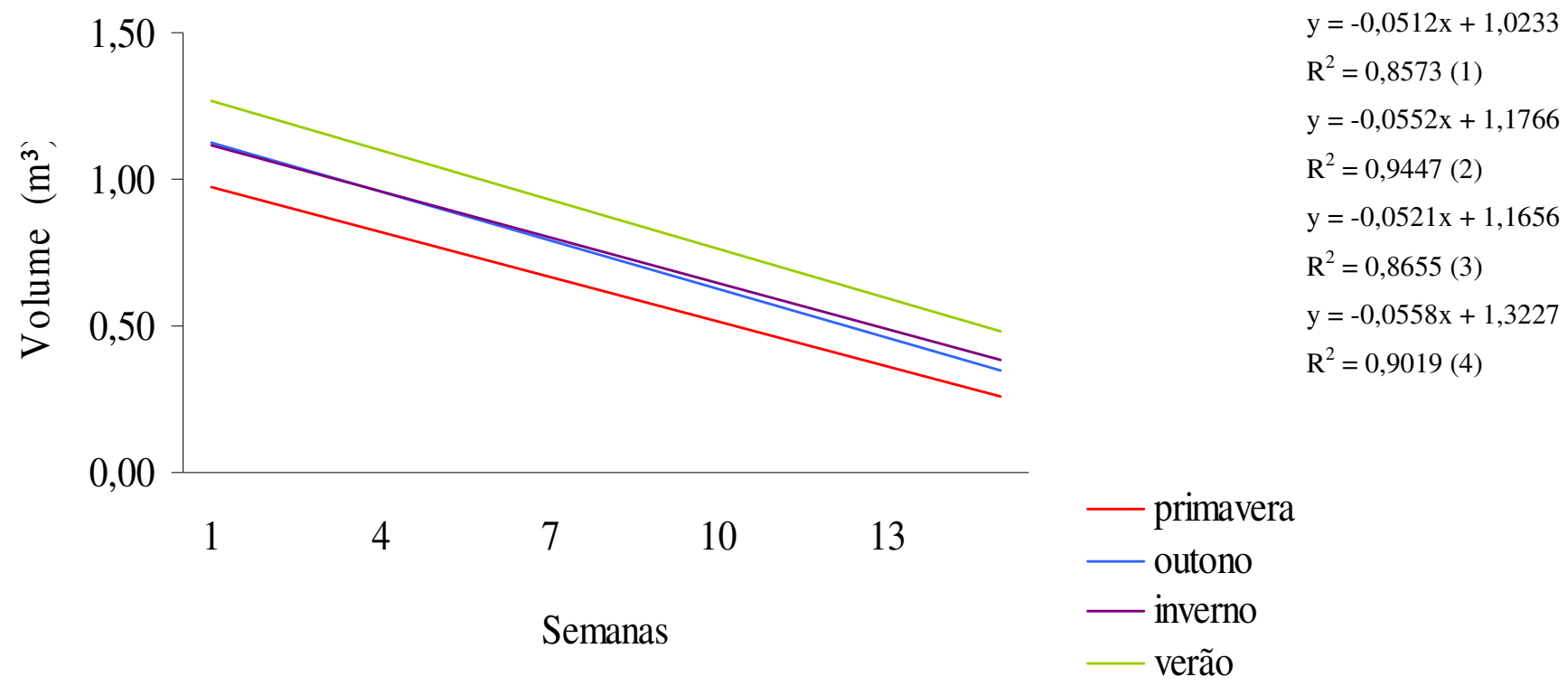

FIGURA 2. Tendências e equações de reduções de volume em leiras de compostagem manejadas durante as estações de primavera (1), outono (2), inverno (3) e verão (4).

Em estudo realizado por GORGATI (2001), com compostagem de lixo urbano, as tendências de redução de volume nas quatro estações foram quadráticas. Tal fato pode estar associado à maior intensidade na fermentação ocorrida durante a compostagem de lixo urbano em relação aos dejetos caprinos, visto que os dejetos são produtos de excreção e já passaram pelo processo de préfermentação, principalmente se forem resíduos de ruminantes, que intensificam a fermentação por meio da câmara ruminal.

As equações encontradas são de importância no planejamento da área a ser utilizada durante o processo de compostagem, já que as reduções foram altas, em média 66,2\%, e devem ser consideradas na ocasião do dimensionamento de pátios de compostagem, pois podem estimar a liberação de área no pátio durante o processo, em função da redução do volume das leiras.

\section{Vermicompostagem}

$\mathrm{Na}$ Tabela 4, estão apresentados os resultados obtidos na vermicompostagem durante as estações de verão, outono, inverno e primavera.

É possível observar que as reduções de MS apresentaram o mesmo comportamento observado na compostagem, ou seja, superior $(\mathrm{P}<0,05)$ nas estações de verão e outono $(55,6$ e 52,2\%, respectivamente) e menor no inverno e primavera (44,5 e 41,6\%, respectivamente).

Em estudo realizado por EGHBALL (1997), avaliaram-se as perdas ocorridas durante o processo de compostagem, utilizando-se de esterco bovino como substrato. $\mathrm{O}$ material permaneceu enleirado por 45 dias e, ao final desse período, apresentou redução de massa de 20,4\%. Tomando-se por base esse último valor, acredita-se que o período de enleiramento tenha sido insuficiente, pois a redução de massa esperada seria de 50\%, segundo KIEHL (1985). 
TABELA 4. Quantidade (em kg) de massa seca (MS), porcentagem de sólidos totais (ST) e voláteis (SV) do esterco enleirado e do vermicomposto, e redução (\%) da quantidade de MS para as diferentes estações do ano.

\begin{tabular}{clcccc}
\hline Parâmetros & \multicolumn{1}{c}{ Período } & Verão & Outono & Inverno & Primavera \\
\hline \multirow{2}{*}{ MS } & Enleiramento & $205,4 \mathrm{~A}$ & $182,5 \mathrm{AB}$ & $242,5 \mathrm{~A}$ & $141,1 \mathrm{~B}$ \\
& Final & $91,2 \mathrm{~B}$ & $87,3 \mathrm{~B}$ & $134,6 \mathrm{~A}$ & $82,5 \mathrm{~B}$ \\
\hline \multirow{2}{*}{$\mathrm{ST}$} & Redução de MS & $55,6 \mathrm{~A}$ & $52,2 \mathrm{~A}$ & $44,5 \mathrm{~B}$ & $41,6 \mathrm{~B}$ \\
& Enleiramento & $19,6 \mathrm{C}$ & $42,0 \mathrm{~A}$ & $37,3 \mathrm{~A}$ & $29,6 \mathrm{~B}$ \\
& Final & $32,8 \mathrm{~B}$ & $33,7 \mathrm{~B}$ & $33,3 \mathrm{~B}$ & $37,0 \mathrm{~A}$ \\
\hline \multirow{2}{*}{$\mathrm{SV}$} & Enleiramento & $80,4 \mathrm{~A}$ & $76,2 \mathrm{~B}$ & $80,4 \mathrm{~A}$ & $80,2 \mathrm{~A}$ \\
& Final & $65,8 \mathrm{~A}$ & $56,6 \mathrm{~B}$ & $69,2 \mathrm{~A}$ & $71,1 \mathrm{~A}$ \\
\hline
\end{tabular}

Médias seguidas de diferentes letras, na linha, diferem entre si, pelo teste de Tukey $(\mathrm{P}<0,05)$.

As reduções de volume observadas durante o período de compostagem foram maiores $(\mathrm{P}<0,05)$ nas estações de verão e outono (48,3 e 45,25, respectivamente), em relação às observadas no inverno e primavera (41,8 e 38,9\%, respectivamente). No entanto, durante a permanência do material no canteiro de vermicompostagem, foram verificadas reduções de volume inferiores e semelhantes em todas as estações do ano, com média de 14,4\%.

Os dados representados na Figura 3 referem-se às temperaturas médias diárias, das leiras de vermicompostagem, nas quatro estações.

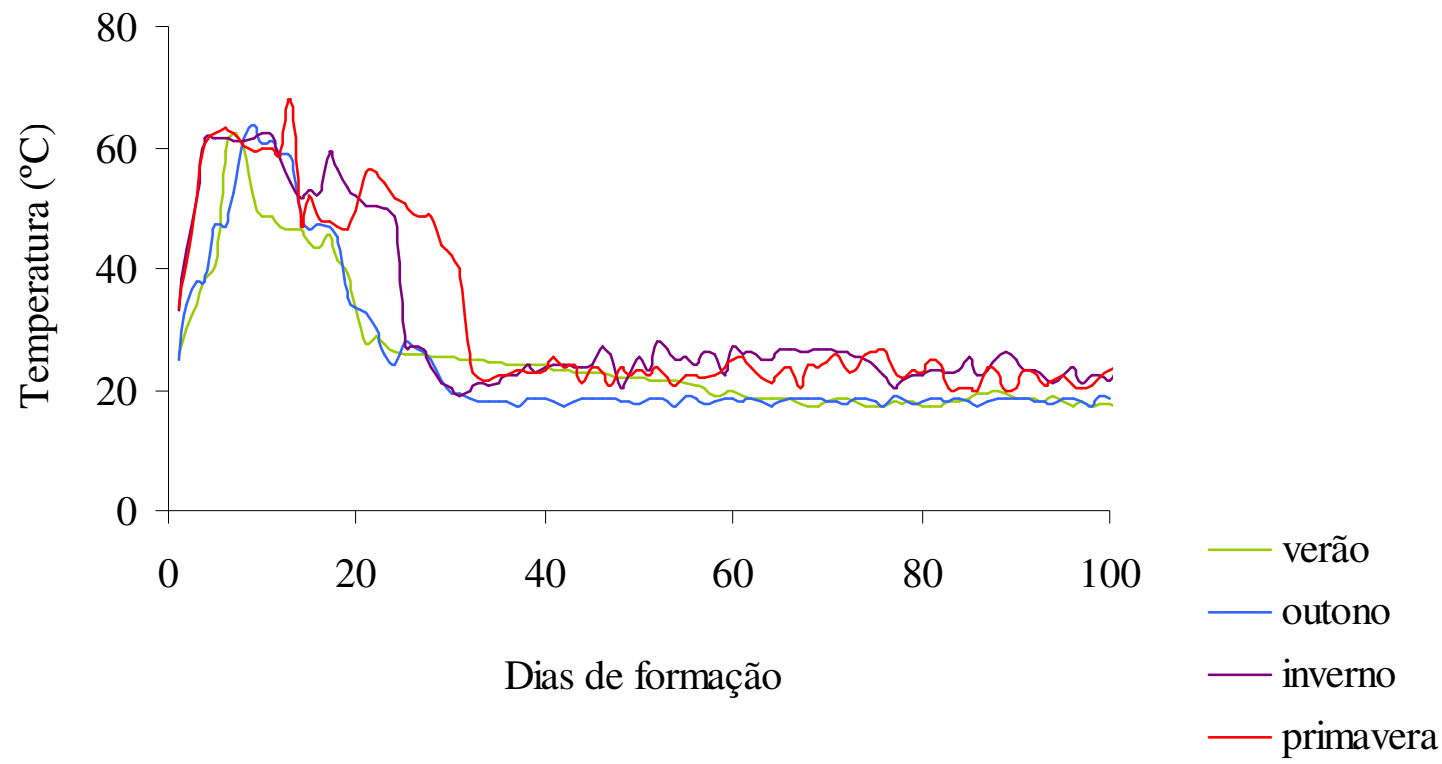

FIGURA 3. Temperaturas diárias das leiras na compostagem e na vermicompostagem durante as estações de verão, outono, inverno e primavera.

O comportamento observado para a temperatura foi semelhante ao do processo de compostagem, que mostra picos menos duradouros nas estações de verão e outono e mais prolongados no inverno e primavera. Observou-se ainda que, a partir de 30 dias de formação das leiras, em todas as estações, a temperatura manteve-se inferior a $30^{\circ} \mathrm{C}$, comportamento que pode estar diretamente associado à transferência da leira para o canteiro de vermicompostagem, com redução na altura de empilhamento em aproximadamente 1,0 m e à eficiência da compostagem. 
$\mathrm{Na}$ Tabela 5, estão apresentados os teores médios de carbono, nitrogênio e relação $\mathrm{C} / \mathrm{N}$ (valores com base na MS) no início e final da vermicompostagem e do vermicomposto nas diferentes estações do ano.

TABELA 5. Teores médios de carbono, nitrogênio e relação $\mathrm{C} / \mathrm{N}$ (\% da $\mathrm{MS}$ ), do esterco enleirado para vermicompostagem e do vermicomposto obtido no verão, outono, inverno e primavera.

\begin{tabular}{clcccc}
\hline Atributo & Período & Verão & Outono & Inverno & Primavera \\
\hline \multirow{2}{*}{$\mathrm{C}$} & Enleiramento & $18,31 \mathrm{~B}$ & $20,66 \mathrm{~B}$ & $26,18 \mathrm{~A}$ & $25,66 \mathrm{~A}$ \\
& Final & $4,63 \mathrm{~B}$ & $8,15 \mathrm{~A}$ & $9,33 \mathrm{~A}$ & $9,45 \mathrm{~A}$ \\
\hline \multirow{2}{*}{$\mathrm{N}$} & Enleiramento & $1,09 \mathrm{~B}$ & $1,17 \mathrm{~B}$ & $1,55 \mathrm{~A}$ & $1,55 \mathrm{~A}$ \\
& Final & $0,47 \mathrm{~B}$ & $0,77 \mathrm{~A}$ & $0,88 \mathrm{~A}$ & $0,91 \mathrm{~A}$ \\
\hline \multirow{2}{*}{$\mathrm{C} / \mathrm{N}$} & Enleiramento & 16,80 & 17,66 & 16,89 & 16,55 \\
\hline Porcentagem de Redução & Final & 4,85 & 10,58 & 10,60 & 10,38 \\
\hline
\end{tabular}

Médias seguidas de diferentes letras, na linha, diferem entre si, pelo teste de Tukey $(\mathrm{P}<0,05)$.

Observou-se efeito $(\mathrm{P}<0,05)$ das estações do ano sobre os conteúdos iniciais e finais de $\mathrm{C}$ e $\mathrm{N}$ e na porcentagem de redução na relação $\mathrm{C} / \mathrm{N}$ ao longo do período de vermicompostagem, com maiores valores, em média, $40,71 \%$, durante o verão e outono, em comparação com os valores observados nas estações de inverno e primavera. Assim como considerado para o processo de compostagem, as estações do ano influenciaram diretamente no processo de vermicompostagem, afirmação confirmada pelas diferenças nas reduções da relação $\mathrm{C} / \mathrm{N}$. Foram encontradas reduções menores na relação $\mathrm{C} / \mathrm{N}$, em comparação com o processo de compostagem. Comportamento inverso foi observado por BANSAL \& KAPOOR (2000), quando conduziram leiras de compostagem e vermicompostagem de esterco bovino, obtendo-se reduções da relação $\mathrm{C} / \mathrm{N}$ de 58,74 e 61,88\% para compostagem e vermicompostagem, respectivamente. É possível notar que a relação $\mathrm{C} / \mathrm{N}$ do vermicomposto foi superior à do composto e muito próxima da definida como ideal por LOPEZ-REAL (1990), citado por GORGATI (2001).

\section{CONCLUSÕES}

As estações têm influência no desenvolvimento dos processos, ocorrendo maiores perdas de carbono e nitrogênio durante o verão e outono, quando comparadas com inverno e primavera, assim como maiores reduções nos teores de MS e do volume ocupado pelas leiras.

As equações obtidas durante a compostagem permitem o dimensionamento de pátios de compostagem, de forma a otimizar a utilização de áreas destinadas aos sistemas de aproveitamento dos dejetos.

\section{REFERENCIAS}

AMERICAN PUBLIC HEALTH ASSOCIATION. Standard methods for the examination of water and wastewater. $19^{\text {th }} \mathrm{ed}$. Washington, 1995. paginação irregular.

BANSAL, S.; KAPOOR, K.K. Vermicomposting of crop residues and cattle dung with Eisenia foetida. Bioresource Technology, Oxford, v.73, n.2, p.95-8, 2000.

EGHBALL, B. Nutrient, carbon and mass loss during composting of beef cattle feedlot manure. Journal Environmental Quality, Madison, v.26, n.1, p.189-93, 1997.

FOOD AND AGRICULTURE ORGANIZATION - FAO 2000. Situación de los mercados de productos básicos. 1997-1998. Disponível em:<www.fao.org.br >. Acesso em: 23 dez. 2001. 
GORGATI, C.Q. Resíduos sólidos urbanos em área de proteção aos mananciais - município de São Lourenço da Serra - SP: Compostagem e impacto ambiental. 2001. 74 f. Tese. (Doutorado em Energia na Agricultura) - Faculdade de Ciências Agronômicas, Botucatu, 2001.

HANAJIMA, D.; KURODA, K.; HAFGA, K. Enhancement of the thermophilic stage in cattle waste composting by addition of the tofu residue. Bioresource Technology, Oxford, v.78, n.2, p.213-16, 2001.

KIEHL, E.J. Fertilizantes orgânicos. São Paulo: Agronômica Ceres, 1985. 492 p.

KNAPPER, C.F.U. Manual de produção de húmus. ABRAMI, 1987. p.21-5. (Boletim informativo, 3)

PEREIRA NETO, J.T.; STENTIFORD, E.I. Aspectos epidemiológicos da compostagem. Revista de Biologia, Uberlândia, v.1, n.1, p.1-6, 1992.

SILVA, D.J. Análise de alimentos: métodos químicos e biológicos. Viçosa: UFV, 1981. 166 p.

THAMBIRAJAH, J.J.; ZULKALI, M.D.; HASHIM, M.A. Microbiological and biochemical changes during the composting of oil palm empty-fruitbunches. Effect of nitrogen supplementation on the substrate. Bioresource Technology, Oxford, v.52, n.52, p.133-44, 1995. 